Article

\title{
Barriers and Bridges to U.S. Forest Service-Community Relationships: Results from Two Pilot Tests of a Rapid Social Capital Assessment Protocol
}

\author{
Jordan W. Smith
}

Department of Forestry and Natural Resources, Purdue University, West Lafayette, IN 47907, USA; E-Mail: smit1547@purdue.edu; Tel.: +1-435-830-6294

Received: 11 September 2012; in revised form: 28 November 2012 / Accepted: 6 December 2012 / Published: 18 December 2012

\begin{abstract}
Successful management of national forests in the United States requires Forest Service personnel to collaborate with the public, including individuals living in communities near national forest lands. Collaboration enables agency personnel to build long-term trusting and reciprocal relationships with local communities through their ongoing planning processes. However, frequently agency personnel do not have the tools or data necessary to measure the strength of relationships that exist between the agency and local communities. A rapid social capital assessment protocol is presented that can be used by agency personnel and social scientists as a tool for gauging the existence and strength of Forest Service-community relationships. The utility of the protocol is illustrated by describing findings from two pilot tests conducted in communities near the Tombigbee National Forest in Mississippi and the Nantahala National Forest in North Carolina. Barriers to effective Forest Service - community relationships are highlighted and opportunities for social capital development, such as utilizing local news outlets, are presented.
\end{abstract}

Keywords: social capital; forest-associated communities; collaboration; Southeastern United States

\section{Introduction}

The USDA Forest Service's philosophical approach to land management has shifted dramatically during the agency's nearly century long existence. Driven by broad social, political, and economic forces, the scientifically grounded conservation philosophies of Gifford Pinchot and other progressives 
have gradually transitioned to a paradigm focused on science-based management. This paradigm provides for multiple uses and multiple benefits from federal forestlands. As philosophical paradigms have shifted, so too have forest planning and management initiatives. In particular, during the last 30 years, planning and management have evolved from a more authoritarian regime, where management decisions were driven primarily by technical experts, to a more collaborative paradigm with proposed management actions being open to public review and comment [1]. For example, the most recent planning directive for the Forest Service called for an increased focus within the agency on collaborative engagement with the public beyond the federally mandated minimum requirements of posting formal notices in the Federal Register and providing a review and comment period on management actions [2].

Despite the agency's increased focus on collaboration, numerous barriers confront agency personnel in their efforts to engage the public successfully. Many of the barriers to collaboration are unique to specific regions of the country and even to specific local contexts [3]. Moreover, particular opportunities to enhance collaboration by building social capital in rural communities may vary by geographic region and the dominant social/cultural norms that are found within those regions. Consequently, successful collaboration requires agency personnel have an acute knowledge of the social and economic conditions within communities near the national forests they manage [3-5]. Unfortunately, however, agency personnel often do not have the tools or data necessary to measure the strength of relationships that exist between the agency and local communities [6].

The primary objective of this paper is to present a data collection protocol that can be used by agency personnel and social scientists to rapidly gather information concerning the strength of relationships which exist between the Forest Service and local communities. The intent behind developing the rapid social capital assessment protocol was to provide Forest Service personnel and other interested parties a mechanism by which they can quickly gather data on community/agency relationships; this data can subsequently be used to inform policy and management decisions that depend on, or impact, local communities. This objective is accomplished by applying the rapid social capital assessment protocol to two communities located adjacent to national forests within the southeastern United States. The utility of the protocol is illustrated by highlighting its capabilities in identifying unique, context specific barriers and bridges to building successful collaborative relationships between the USDA Forest Service and the local communities. The study is exploratory and the findings are not meant to be generalizable across all forest-associated communities in the southeastern United States

\subsection{Background}

The explicit purpose of the transition toward collaborative management is to streamline and improve the planning process over the long run by making plans more adaptable to changes in social, economic and environmental conditions [7]. The belief being that if all stakeholders, including local community members are involved in making Forest Service decisions, each will be more aware of the others' needs and objectives. By establishing a relationship with stakeholders, the agency can gain individuals' trust and mitigate potential legal or social friction that may result from agency decisions. 
Simultaneously, collaborative efforts enable stakeholders to weigh in on proposed actions thereby ensuring that the agency is aware of how its decisions affect their lives and livelihoods.

Collaboration is believed to make current planning processes more efficient over time as stakeholders involved in one forest management issue are likely to be involved in subsequent issues [6]. Collaboration builds social capital, on which the agency and stakeholders can draw as new issues arise. Social capital is defined here as the collective value of resources available to individuals or organizations through their social networks. This definition follows directly from sociologist Pierre Bourdieu who defined it as "the aggregate of the actual or potential resources which are linked to possession of a durable network of more or less institutionalized relationships of mutual acquaintance and recognition" [8]. The aphorism, "it's not what you know, it's who you know," sums up much of the conventional wisdom surrounding social capital. More specifically, social capital is not a characteristic of individuals and/or organizations; rather, it is an aggregate of resources accessible to those individuals/organizations within a social network [9]. Access to social capital can be facilitated when individuals who know each other share feelings of reciprocity, trust and positive emotion toward each other. When community members and Forest Service managers and staff mutually share these feelings, they are more readily able to invest in and draw on this social capital to achieve desired goals. In other words, strong social networks that engage community members and Forest Service personnel facilitate exchange of both traditional and scientific knowledge, mobilize collective action and increase accountability.

Within the context of Forest Service - community relationships, several recent studies reveal that agency investment in building strong reciprocal relationships with community members can mitigate the effects of disagreements and more efficiently meet management objectives. For example, the strength of relationships between grazing permit holders and the agency in Nevada was found to significantly mitigate negative feelings after the agency made a decision with which the permit holder did not agree [10].

Recent research also suggests that agency personnel believe trusting relationships with local community members are important for the proper functioning of the agency [11]. In interviews with community members and agency personnel near the Midewin National Tallgrass Prairie in northern Illinois, Davenport, Leahy, Anderson, and Jakes [4] found that the community members and the agency personnel related trust with resource stewardship and effective natural resource management. For instance, trusting relationships were believed to enable a greater ability to initiate and sustain volunteer efforts, essential to prairie restoration projects.

Stronger social ties and feelings of trust across those ties are frequently viewed as a non-economic mechanism to reduce future costs for the Forest Service $[6,12]$. This benefit is increasingly important as many national forests struggle with escalating costs of programs such as fire prevention and suppression [13] and recreation [14]. Forest Service efforts to build social capital within communities and between the agency and communities can help to reduce such escalating costs [15]. For example, the Healthy Forests Restoration Act of 2003 included a provision that Forest Service offices, in collaboration with local communities, develop Community Wildfire Protection Plans in an effort to actively engage citizens in wildfire mitigation and response activities. Recent research within the agency on the development of these Community Wildfire Protection Plans (which directly attempt to establish or strengthen community/agency ties) suggests they have been successful in reducing local 
distrust of the agency, and more importantly, decreasing the likelihood of the agency being litigated over its fuels reduction and fire suppression practices [16,17].

The benefits of building social capital between the Forest Service and local communities are not accrued solely by the agency; local communities stand to gain as well. For example, Agrawal and Monroe [18] found that communities with stronger relationships to the Forest Service are better able to work together and cope with the problems of wildfire threat. In a similar study, Brenkert, Champ, and Flores [19] found that individuals living near national forests in Wyoming, who had developed a one-on-one relationship with agency personnel, were more likely to implement wildfire mitigation measures.

More broadly, the benefits accrued to community members from the development of strong social ties to the agency emerge from being able to be more directly involved in the decisions affecting the resource, and in turn, their lives and livelihoods. Community members, whether they use national forests for their own economic, social or psychological benefit, have a stake in conserving forest resources and services.

According to Wondolleck and Yaffee [6], the ability of Forest Service personnel to develop successful relationships with stakeholders and local communities has been mixed. The agency particularly struggled during in the 1970s and 1980s when there was little to no guidance about how to plan and manage Forest Service lands collaboratively. During this same time, local units within the Forest Service began to feel heavy pressure to appease not just the needs of local individuals, but broader national and political interests as well [20]. Since that time, however, the agency has placed much greater focus on collaborative approaches, especially since the introduction of Ecosystem Management in the early 1990s [21]. Consequently, a small body of literature focused on identifying potential barriers or pitfalls to social capital development has emerged.

\subsection{Barriers to Social Capital Development}

Though the benefits of strong social ties between the Forest Service and local communities are numerous, significant barriers, both attitudinal and organizational, inhibit the development of these relationships.

Attitudinal barriers to social capital development can be outside of the control of the Forest Service. Arguably, the largest attitudinal barrier faced by agency personnel is declining levels of trust in government [22]. This lack of trust communities have in government impacts forest managers directly since individuals with low levels of trust in government also express low levels of trust in federal land management agencies and agency personnel [23-25]. Trust or lack of it is not a new phenomenon, as foresters have been attempting to manage public perceptions and trust for decades [26].

Attitudinal barriers to social capital development also include community members' general level of apathy toward management decisions [27]. Past agency decisions or feelings of animosity over past government actions are also likely to negatively influence agency personnel's ability to foster trusting and positive relationships with individuals with whom they interact [4].

Organizational barriers to social capital development are those within the agency. They can be grouped into two categories: (1) those related to agency structure; and (2) those related to agency norms and culture (Table 1). They have been well documented [6,27,28]. For example, 
Lachappelle et al. [27] and Selin et al. [28] point out that major structural barriers that get in the way of building strong community/agency relationships include the perceived centralized power structure of the agency, inflexible policies and procedures and goals that often conflict with community goals. Davenport et al. [11] found that agency personnel tend to rely too much on traditional public involvement methods (open comment periods and agency presentations of proposed management actions) that community members often perceive to be unfair.

Table 1. Agency barriers to building forest service—community relationships.

\begin{tabular}{|c|c|c|c|c|}
\hline \multirow[b]{2}{*}{ Barrier and type } & \multicolumn{4}{|c|}{ Study or meta-analysis } \\
\hline & $\begin{array}{l}\text { Wondelleck and } \\
\text { Yaffee 2000 } \\
\end{array}$ & $\begin{array}{l}\text { Selin, Schuett, } \\
\text { and Carr } 1997 \\
\end{array}$ & $\begin{array}{l}\text { Lachapelle } \\
\text { et al. } 2003^{\text {a }}\end{array}$ & $\begin{array}{l}\text { Davenport, } \\
\text { et al. } 2007\end{array}$ \\
\hline \multicolumn{5}{|c|}{ Structure of the agency } \\
\hline Constrained Resources (time and money) & $\times$ & - & - & $\times$ \\
\hline Conflicting goals and missions & $x$ & $x$ & $x$ & - \\
\hline Centralized power structure & - & $x$ & $x$ & $x$ \\
\hline Increased departmentalism & - & - & - & \\
\hline Too much focus on accountability & - & - & - & $x$ \\
\hline Inflexible policies and procedures & $\times$ & $\times$ & $x$ & - \\
\hline \multicolumn{5}{|c|}{ Agency norms and culture } \\
\hline $\begin{array}{l}\text { Reliance on traditional public } \\
\text { involvement techniques }\end{array}$ & $x$ & - & - & $x$ \\
\hline Lack of opportunities or incentives & $x$ & $x$ & - & - \\
\hline Too much use of technical jargon & - & - & - & $x$ \\
\hline Too much staff turnover & - & - & - & $\times$ \\
\hline $\begin{array}{l}\text { Personnel not interacting with } \\
\text { community members on personal time }\end{array}$ & - & - & - & $\times$ \\
\hline $\begin{array}{c}\text { No collaborative training or } \\
\text { skill development }\end{array}$ & $x$ & $\times$ & - & - \\
\hline
\end{tabular}

a: These studies analyze other federal land management agencies' connections to local communities as well as Forest Service relationships; $\times$ : Barrier discussed in study or meta-analysis.

\section{Methods}

A research team of social scientists from within and outside of the Forest Service was commissioned with developing a rapid social capital assessment protocol that could be used by the agency to standardize and expedite data gathering relevant to the relationship between the Forest Service and the local communities that reside near national forests. The primary purpose of developing a rapid social capital assessment protocol was to provide the agency with a tool through which they could rapidly and efficiently collect data on the strength of social relationships between themselves and local communities. The rapid social capital assessment protocol is not intended to provide a robust, highly rigorous and completely objective assessment of the relationship between local communities and the agency; this follows generally accepted guidelines for rapid social assessments [29].

Independent social scientists, or trained Forest Service personnel, are intended to follow the rapid social capital assessment protocol. The use of external social scientists for data collection is preferred 
given the conflicts of interests between agency personnel collecting data concerning their employer. All data collection processes outlined in the protocol are designed to be completed in approximately one-week. The data, and subsequent technical reports, are intended to inform future agency discussions that involve policies and management decisions that affect local communities.

The rapid social capital assessment protocol design (Figure 1) is comprised of three distinct data collection processes:

1. Two checklists to identify the presence, absence and trajectory of various social capital indicators;

2. A workshop involving both agency personnel and community members;

3. And a rating sheet completed by workshop participants concerning perceptions of their community's stock of social capital as well as the social capital within the community/agency relationship.

Figure 1. Rapid Forest Service — community social capital assessment protocol design.

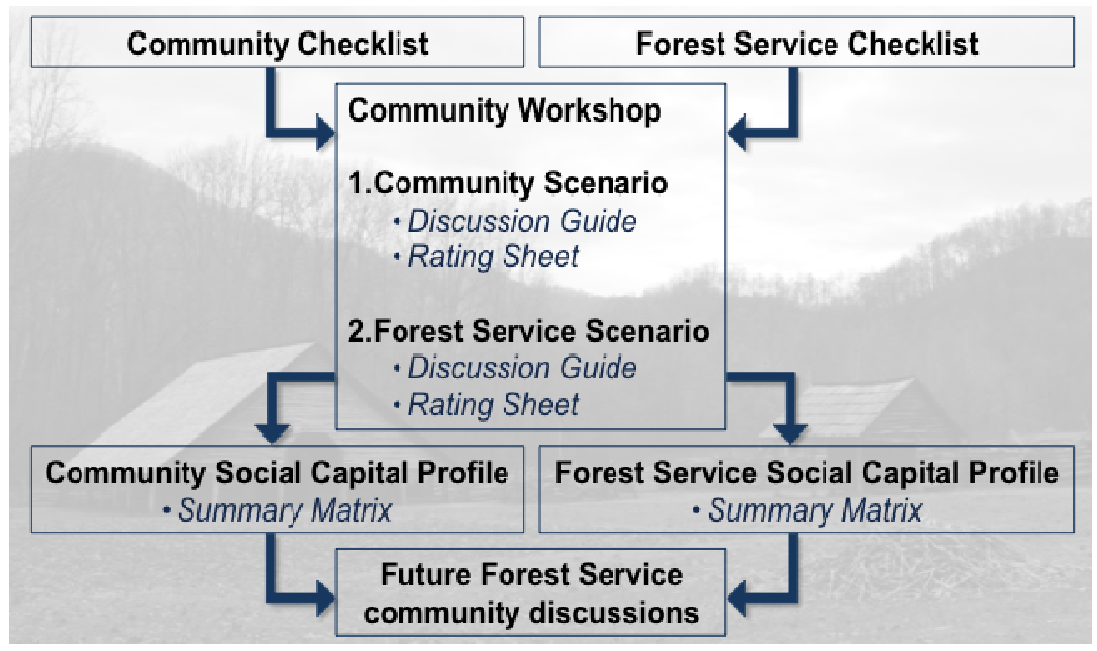

\subsection{Community and Forest Service Checklists}

Two sets of social capital checklists were developed. The first community social capital checklist assesses the presence, absence and trajectory of social capital indicators within the community (Figure 2). Based on a review of the literature, the research team identified five categories of indicators that enabled an assessment of the amount of social capital within a community. For each category, a set of two to five indicators was created. Social scientists completed the checklists by contacting city officials and other informed community members who were willing and able to discuss their community's organization and operation. 
Figure 2. Community social capital checklist.

Community Social Capital Checklist

\section{Instructions for using this checklist:}

This checklist is to be completed by the person doing the social capital assessment, prior to the community workshop. It should consist of information that is either readily available through existing documents or is reliably accessible through conversation with 1-2 informed community residents, leaders, or employees (such as a town clerk or planner). The checklist is organized by category of social capital. Other indicators that are more easily obtainable and appear to measure a similar condition or characteristic may be subsituted for individual checklist items, but try to complete as many checklist items as possible.

Categories

Checklist questions to be addressed with the following in mind:

I. Collective Actions

Is there evidence of collective action in the community that likely reflects the use and/or building of social capital?

II. Social Structure

III. Demographics Does the community's social structure facilitate creation and use of social capital?

What information about community residents and trend

IV. Built Environment (Infrastructure) may be related to the presence or use of social capital?

v. Information \& Does the community's built environment lend itself toward building social capital, or reflect its presence?

Communication

Key to Using the Community Checklist

It is recognized that a straightforward (a) presence or absence of the indicator is not usually adequate for understanding some of the information sought through this checklist. Therefore, positive and negative $(+/-)$ trend/condition indicators are provided to enable a consistent reporting format while offering the researcher systematic tools to remark on the specific trend or condition, whether or not present.

\begin{tabular}{ll} 
Exists/Does not exist $(\checkmark)$ & $\begin{array}{l}\text { For each question or consideration posed in the Community Checklist a check should be entered into the appropriate column (e.g. } \\
\text { Yes/No) to indicate whether or not the specific indicator is present. }\end{array}$ \\
\hline $\begin{array}{l}\text { Exists, with positive trend or } \\
\text { condition }(+)\end{array}$ & $\begin{array}{l}\text { If an indicator is present, provide additional detail. Where the trend or condition of the indicator appears to be positive or increasing, a + } \\
\text { should be entered into the appropriate column. Use the "Notes" space to add any comments. }\end{array}$
\end{tabular}

Community Social Capital Checklist

Presence of Social Capital Factors

\section{Collective Action Indicators}

Volunteerism-look for evidence within community (and specific

to FS): density and incidence in membership in volunteer eroups,

hours spent working on projects; other contributions to

community efforts.

1. In the most recent local election, were there any bond issues; if so, what type were they, did they pass, and by what margin?

e.g. Schools

e.g. Parks

2. Presence of community gardens or similar public places/spaces available to residents.

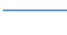

3. Does the community have a fire district or similar entity? ves, how many of the positions are volunteer and how many are paid?

How easy or difficult is it to insure adequate numbers of volunteers are available?

4. What other activities ongoing in the community involve the use of volunteers?

a)

b)

c)

5. community events and celebrations (name of event, attendance trends)

b)

d)

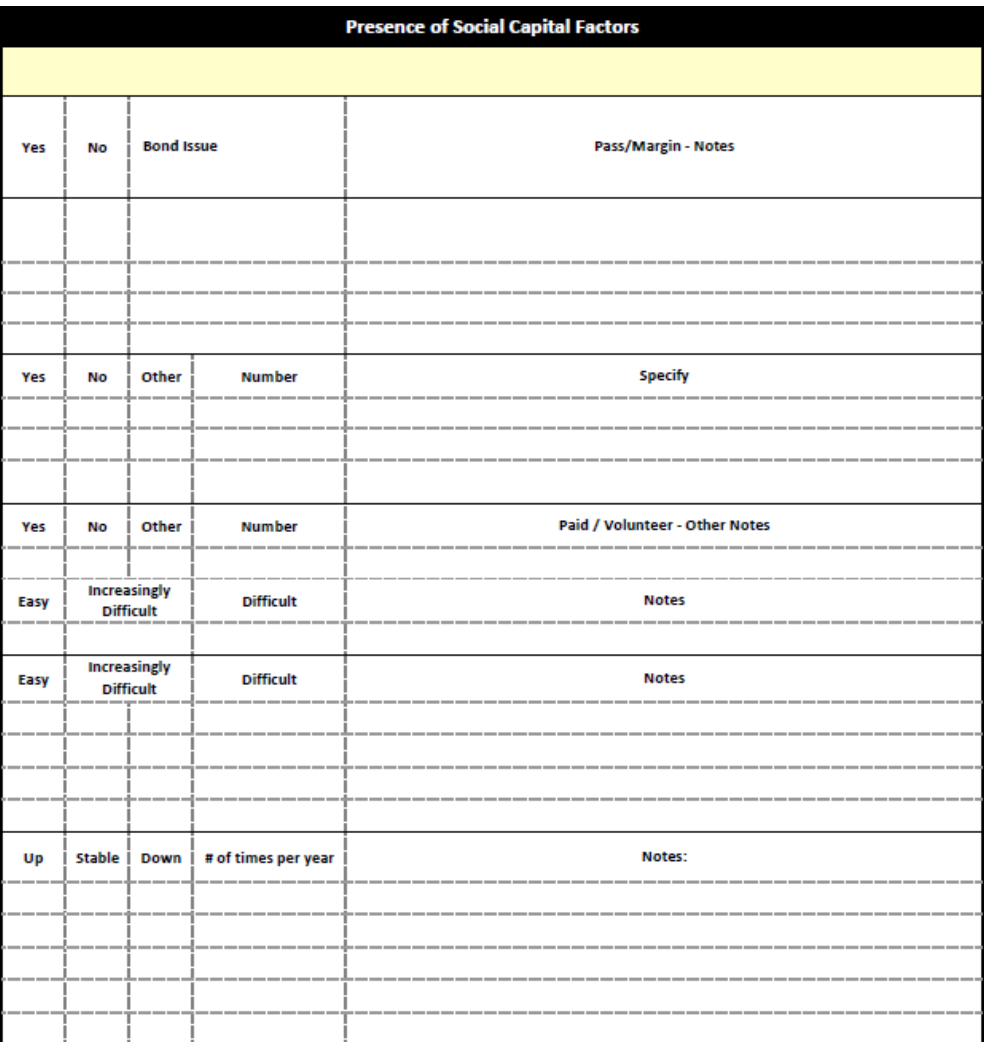


Figure 2. Cont.

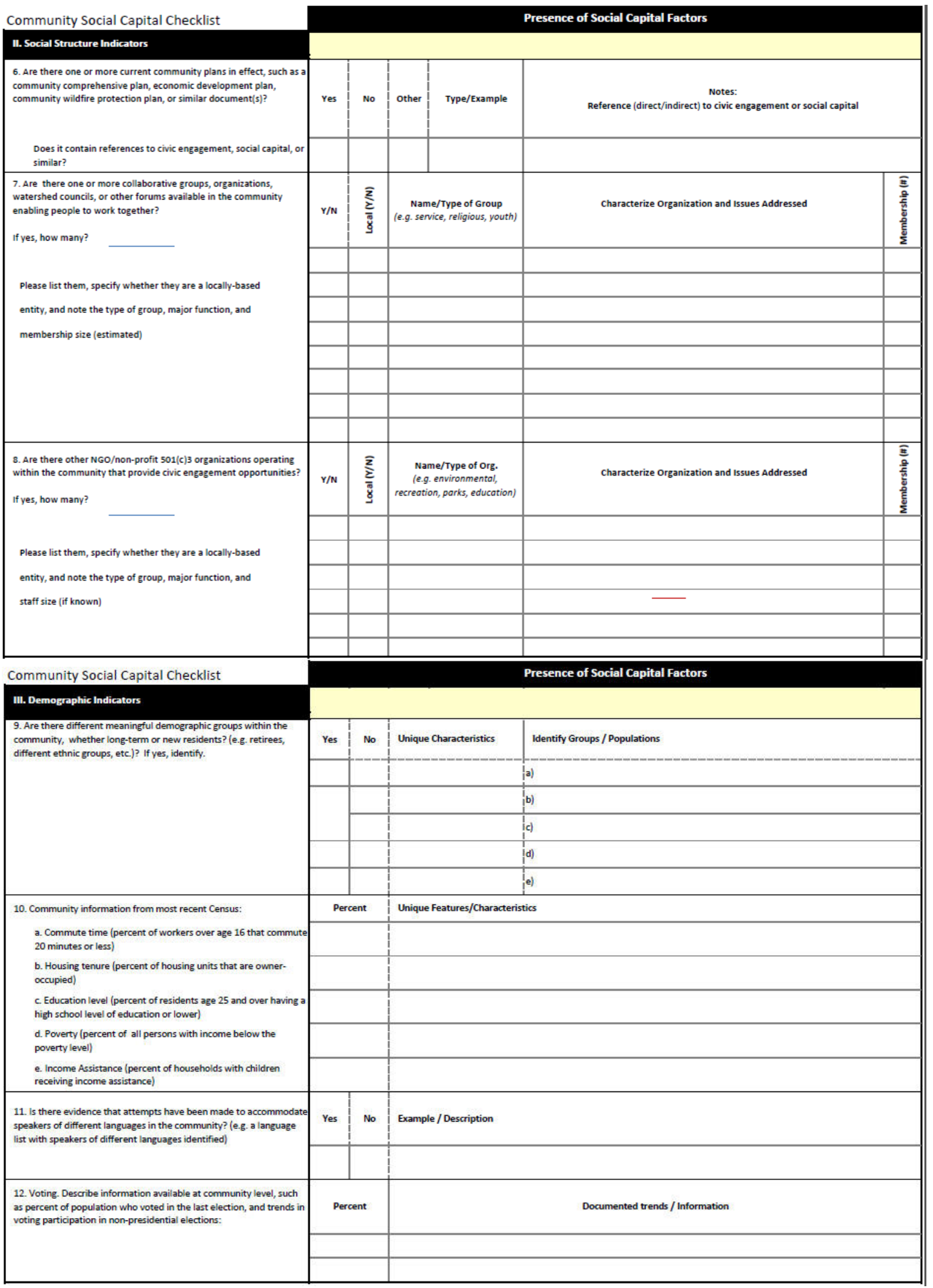


Figure 2. Cont.

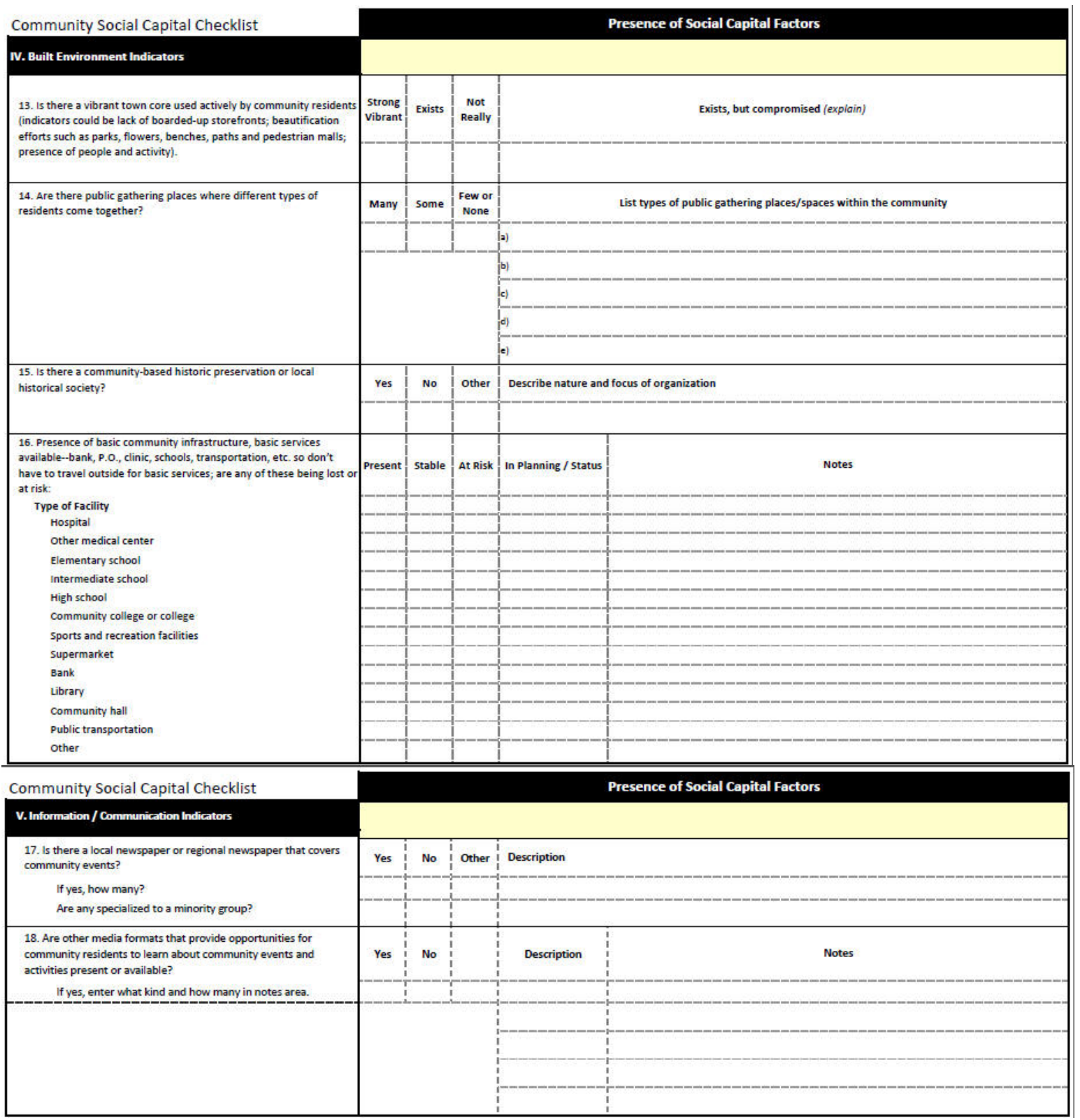

The second Forest Service social capital checklist assessed the presence, absence and trajectory of social capital between the Forest Service and the community (Figure 3). Again, based on the existing literature, the research team identified two broad categories of Forest Service-community social capital measurement. These categories, community integration and community engagement, were subsequently gauged using a series of 16 indicators; they were measured via contacts with Forest Service personnel, city officials and informed community members. 
Figure 3. Forest service social capital checklist.

\section{Forest Service Social Capital Checklist}

\section{Instructions for using this checklist:}

This checklist should be completed by the person doing the social capital assessment prior to the community workshop. It consists of information that is either readily available through existing documents or is reliably accessible through conversation with 1-2 knowledgeable Agency employees, such as a District Ranger, Volunteer Coordinator, Public Affairs Officer, or Community Liaison. The checklist is organized by category of agency social capital. Other indicators that are more easily obtainable and appear to measure a similar condition or characteristic may be subsituted for individual checklist items, but try to complete as many checklist items as possible. Identify the name of the Forest/Unit being assessed (i.e., Deschutes NF/Sisters RD) and the name of the associated community.

Categories

Checklist questions to be addressed with the following in mind:

I. Community Integration

Is there evidence that the agency and its locally-based employees are active participants in community activities, as agency employees or community members? Is the agency a good neighbor apart from its land management and other duties?

II. Community Engagement Is there evidence of alliances and partnerships with the community that reflects the use and/or building of social capital? Does the Agency's structure facilitate creation and use of social capital in attaining its goals?

Guide to Using the Forest Service Checklist

It is recognized that a straightforward presence or absence of the indicator is not usually adequate for understanding some of the information sought through this checklist. TTherefore, positive and negative $(+/-)$ trend/condition indicators are provided to enable a consistent reporting format while offering the researcher systematic tools to remark on the specific trend or condition.

Exists/Does not exist $(\checkmark) \quad$ For each question or consideration posed in the Community Checklist a $(\checkmark)$ should be entered into the appropriate column (e.g. Yes/No) to indicate whether or not the specific indicator is present (or enter the \%, as needed)

Exists, with positive trend or In most cases, it will beuseful to provide additional detail. Where the trend or condition of the indicator appears to be positive condition (+) or increasing, a + should be entered into the appropriate column. Use the "Notes" space to add comments.

Exists, with

compromised/negative Where the trend or condition appears to be negative or decreasing, a - should be entered into the appropriate column. Use trend or condition (-) the "Notes" space to add any comments.

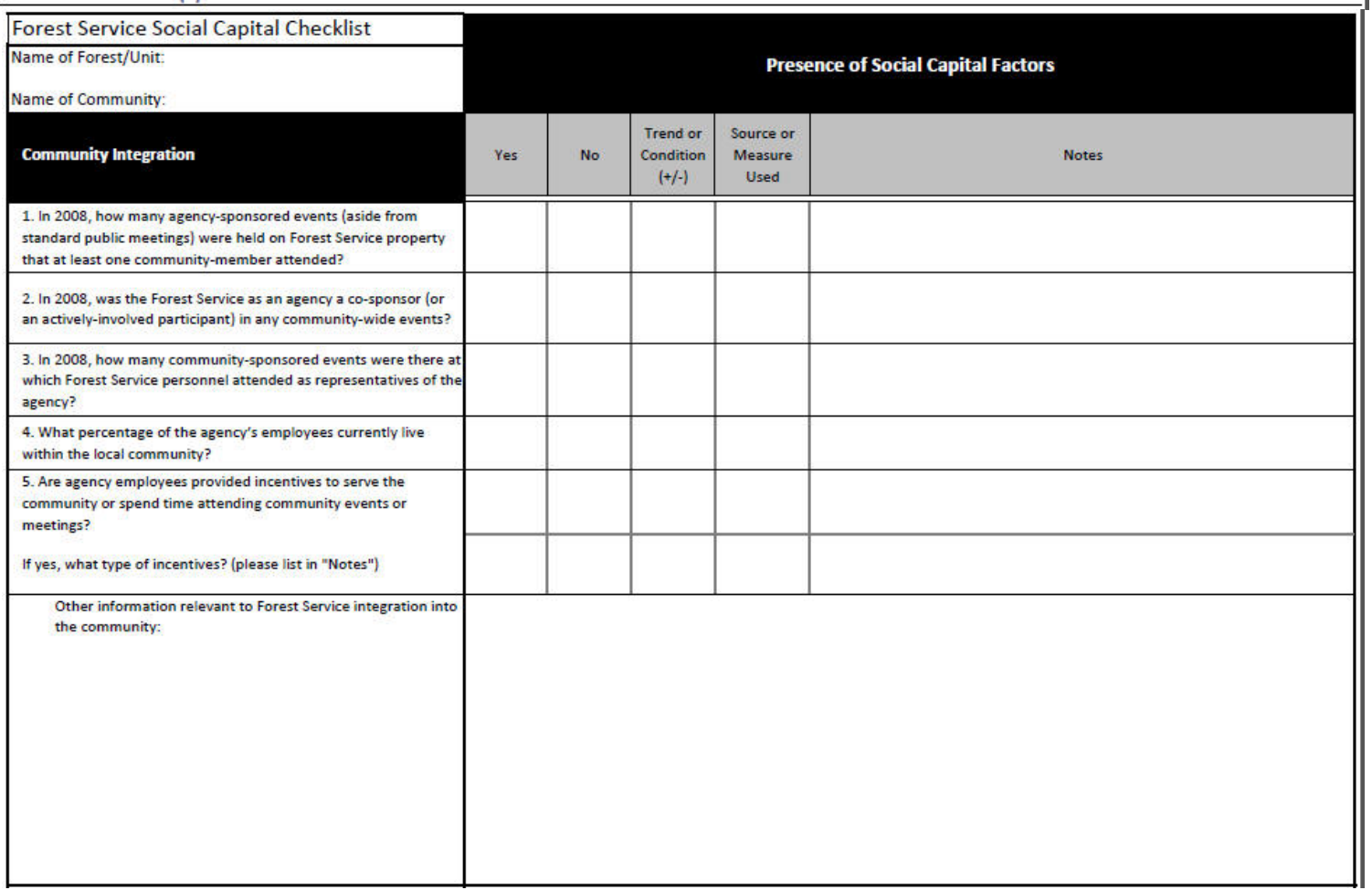


Figure 3. Cont.

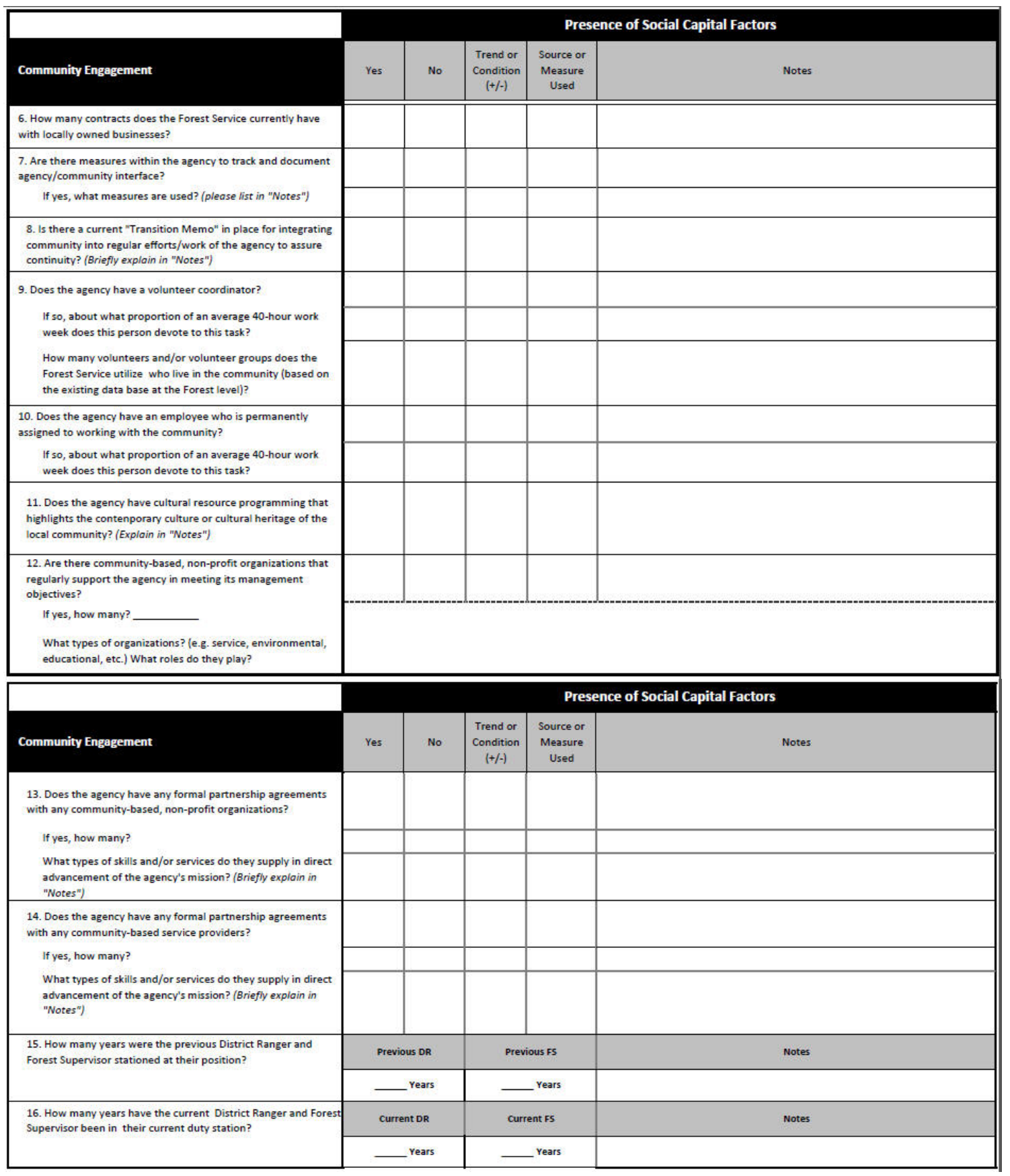

\subsection{Workshops}

The workshops developed as part of the rapid social capital assessment protocol were designed to engage local community members and Forest Service personnel in discussion on two topics: (1) how the community is or has been able to engage in collective actions (e.g., passing bonds or organizing community revitalization efforts); and (2) how the community is or has been able to mobilize resources either against, or in support of, Forest Service management actions. Discussion on the first topic is intended to provide an understanding about the existing stocks of social capital within the community 
and if those resources could be mobilized to address community-wide needs. Discussion on the second topic is intended to provide an understanding about how the agency and the community have interacted in the past and how they perceive their capacity to collaborate in the future. The full guidelines detailing how the workshops were conducted is included in Supplementary File 1-Discussion Guide. After completion of the workshops, community members and Forest Service personnel were asked to complete a brief rating sheet, which is included in Supplementary File 2-Rating Sheet.

\subsection{Community and Forest Service Social Capital Assessment Matrices}

Based upon the data gathered through the completion of both the community and the Forest Service checklists, as well as the completion of the workshops, the rapid social capital assessment protocol calls for the investigator to make an informed decision regarding the presence/absence and trajectory of social capital within the study community. The protocol also calls for the investigator to use the data to gauge the presence/absence and trajectory of social capital existing between the community and the Forest Service. Both of these assessments are completed through simple matrix diagrams (Figures 4 and 5). Importantly, the primary purpose of having the investigator make these assessments is to inform future agency discussions that involve policies and management decisions that require or affect local communities.

Figure 4. Example of completed community social capital assessment matrix.

\begin{tabular}{|c|c|c|c|c|c|c|c|c|c|}
\hline \multirow[b]{3}{*}{ Source: } & ry of Commun & y Social Capit & actors: & Name of comm & nity: Louisville & & & & \\
\hline & \multicolumn{9}{|c|}{ Factors } \\
\hline & Collective Actions & Social Structure & Demographics & $\begin{array}{l}\text { Built Environment } \\
\text { (Infrastructure) }\end{array}$ & $\begin{array}{l}\text { Information \& } \\
\text { Communication }\end{array}$ & Civic Dialogue & $\begin{array}{l}\text { Perceived Social } \\
\text { Capital }\end{array}$ & Human Capital & Results \\
\hline Checklist & $\Rightarrow$ & & & & & $\mathrm{X}$ & $X$ & X & $X$ \\
\hline Workshop & & $\Leftrightarrow$ & X & & & $\Leftrightarrow$ & $\Rightarrow$ & & \\
\hline Summary & & & & & & $\Leftrightarrow$ & $\Rightarrow$ & & \\
\hline KEY & & & & & & & & & \\
\hline
\end{tabular}

Figure 5. Forest Service social capital assessment matrix.

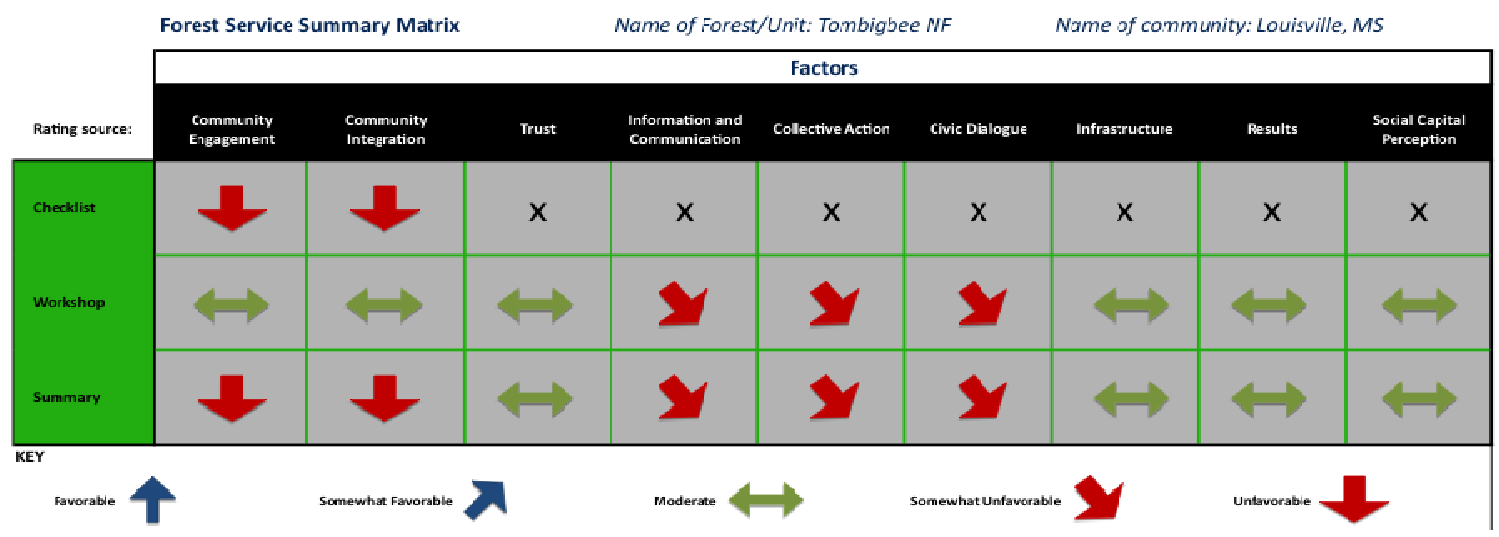




\subsection{Community Selection}

The rapid social capital assessment protocol was pilot tested in two distinctly different communities within the southeastern United States; these two communities were Louisville, Mississippi and Franklin, North Carolina. Both study communities border national forests and were selected because they differ in their socio-economic profiles and have distinctly different relationships (i.e., economic dependence, recreational opportunities, etc.) with their respective national forests. These distinctions are described following the description of both communities and their surrounding national forests.

\subsubsection{Louisville, Mississippi and the Tombigbee National Forest}

The community of Louisville is located in north-central Mississippi and abuts the 66,576-acre Tombigbee National Forest. Louisville is rural, with a 2008 population estimate of 6,604 [30]. The population has been steadily declining since 1990 .

The history of Louisville's local economy is rooted in the expansion of plantation agriculture that characterized much of the southeastern United States through the late 1800s. Forest-related employment (i.e., agricultural services, forestry, hunting and fishing) within the area has always been relatively marginal when compared to agricultural related jobs (Figure 6). However, within the past several decades, employment in forest-related industries has increased [31].

Figure 6. Population and employment in natural resource related industries from 1971 to 2007 within Winston County, Mississippi. Louisville is the county seat of Winston County [31].

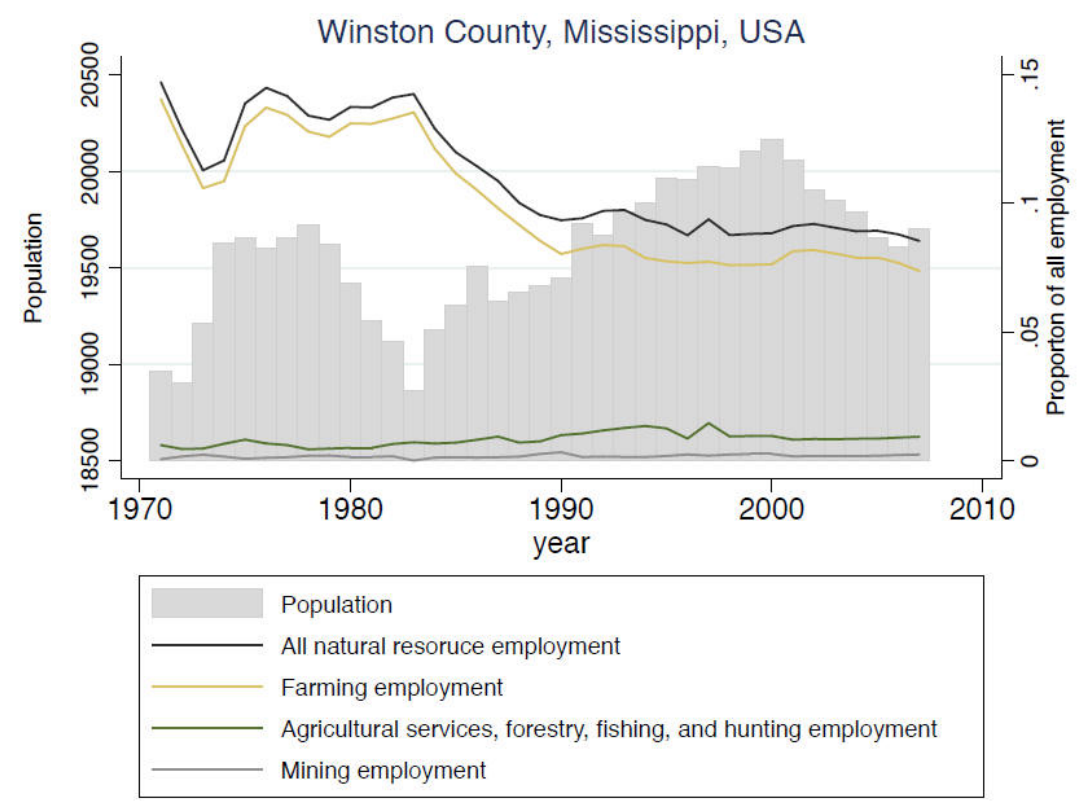

The Tombigbee National Forest is a part of the National Forests of Mississippi, a consolidated administrative unit that includes the Bienville, Delta and Chickasawhay, De Soto, Homochitto, and Holly Springs National Forests. Recreational opportunities provided on the Tombigbee include two lakes (Choctaw and Davis), a 15-mile horse trail, and numerous hiking, mountain biking trails as well as hunting and fishing opportunities. 


\subsubsection{Franklin, North Carolina and the Nantahala National Forest}

Franklin, a community of nearly 4,000 individuals [30], is located in extreme western North Carolina. In contrast with Louisville, which has lost $8 \%$ of its population since 1990, Franklin has been growing relatively rapidly. Between 1990 and 2008, the population grew by roughly $38 \%$. Most of this growth is attributable to Franklin's forested landscape and proximity to metropolitan areas (e.g., Asheville, Atlanta, Knoxville); both of these factors tend to attract a disproportionate number of retirees looking for a slower pace of life while simultaneously having access to needed medical and social services [32].

Franklin neighbors the 531,286-acre Nantahala National Forest. The Nantahala is comprised of three ranger districts (Cheoah, Nantahala, Tusquitee) and is managed under the National Forests of North Carolina administrative unit that includes the Croatan and Pisgah National Forests. Similar to Louisville, Mississippi, forest-related industry plays a marginal role in Franklin's overall economy (Figure 7). Forest related industries have never accounted for more than two percent of total employment near Franklin [31]. Also similar to the Tombigbee National Forest, the Nantahala provides a vast array of recreational opportunities to the residents of Franklin, North Carolina. These recreational activities include: hiking, mountain biking, swimming, hunting, fishing, camping and driving (a large proportion of the Blue Ridge Parkway runs through the Nantahala National Forest).

Figure 7. Population and employment in natural resource related industries from 1971 to 2007 within Macon County, North Carolina. Franklin is the county seat of Macon County [31].

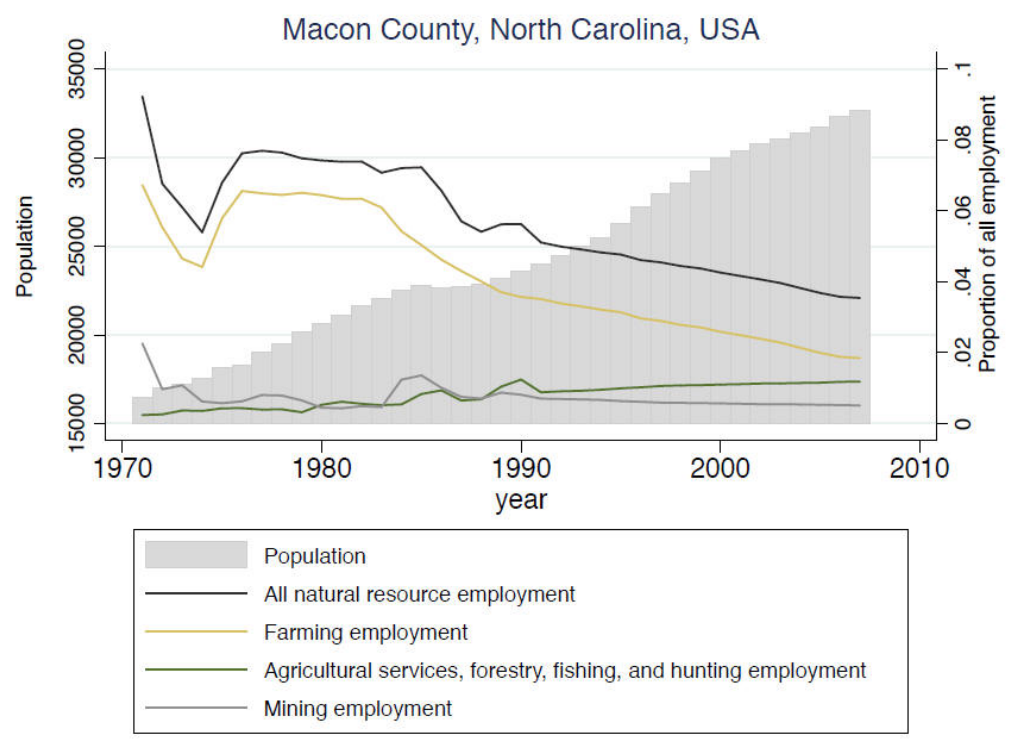

\subsubsection{Key Distinctions Between the Two Study Communities}

While employment in the forest sector is only a marginal component of the economies of both Louisville and Franklin, the economic composition of both communities is notably different. Specifically, forest related employment is the dominant source of natural resource based employment within Macon County, North Carolina (Franklin is the county seat of Macon County) (Figure 8). Nearly 35 percent of natural resource employment comes from the forest sector in the area around 
Franklin. This fact contrasts with the Mississippi study community where less than 10 percent of all natural resource employment comes from the forest industry. This difference was an important factor in sample site selection given our intention of exploring the extent to which the rapid social capital assessment protocol could be applied to different socio-economic contexts. Other factors influencing site selection were large variations in the educational attainment, average income levels and racial composition between the two cities (Table 2).

Figure 8. Employment in agricultural services, forestry, fishing, and hunting as proportion of all natural resource employment from 1971 to 2007 for both study communities.

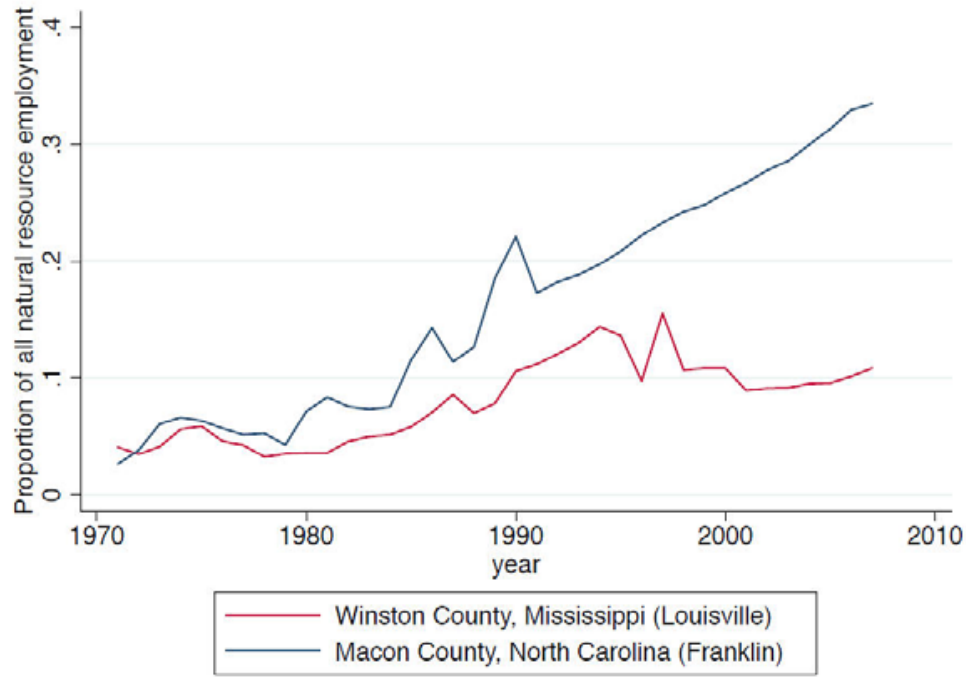

Table 2. Sociodemographic differences between study communities.

\begin{tabular}{ccc}
\hline Distinctions & Louisville, Mississippi & Franklin, North Carolina \\
\hline Median age (years) & 34.9 & 40.5 \\
Race/Ethnicity (percent) & - & - \\
White & 36.5 & 98.3 \\
Black or African American & 61.6 & 2.1 \\
Hispanic or Latino & 0.8 & 13.0 \\
Other & 0.9 & 6.1 \\
Average household size & 2.55 & 2.20 \\
Average family size & 3.13 & 2.88 \\
Educational attainment for population 25 years. and older & - & - \\
High school graduate (includes equivalency) & 83.7 & 78.7 \\
Bachelor's degree or higher & 20.0 & 19.5 \\
Income & - & - \\
Median earnings in past 12 months (in 2010 \$US) & 22,433 & 25,055 \\
\hline
\end{tabular}

\section{Findings}

Data collected from the checklists and workshops were intended to assess either the stocks of social capital within the community or the stocks of social capital between the community and the Forest Service. The findings presented here represent the data collected through both the community and 
Forest Service checklists and the community/agency workshops. The findings below highlight how the rapid social capital assessment protocol was able to identify unique characteristics of social capital within each community and between the agency and each community. The presentation order of the findings follow the indicator categories specified in both the community and Forest Service checklists.

\subsection{Community Checklists}

\subsubsection{Demographics}

None of the community leaders or Forest Service personnel contacted in Franklin, North Carolina indicated that meaningful differences existed between the community's distinct socio-demographic groups. This was unexpected given the community's recent population growth, much of which is attributable to retirees migrating into the area or purchasing second homes. Conversely, in Louisville, several of the community members interviewed, including the town's mayor, expressed concern over the apparent social divisions within the community. These individuals conveyed that people within their community tended to "stick to their own groups" and did not interact with others perceived as different. Several of these individuals suggested these social divisions occur along racial and denominational lines.

\subsubsection{Built Environment}

The built environment, and the emotional and affective ties it evokes, can provide significant bridges to establishing trust and reciprocal relationships between the agency and local community members. In both Franklin and Louisville, strong attachments to each area's local history and architecture were noted. Franklin and Louisville have quite vibrant downtown areas that are actively used to preserve their area's heritage (both communities have established active community-based historic preservation societies) and attract tourists; thereby boosting local sales receipts. The downtown areas also served as focal points for public life, providing staging areas for Farmer's markets, community parades and youth and family events.

\subsubsection{Community Economy}

A barrier to Forest Service - community relationships lies in the role the agency plays in local economies. Nearly all of the Louisville community members interviewed expressed sentiments that conveyed a lack of desire to be involved in Forest Service decisions simply because they believed the agency had little if any connection to their economic well-being. An agency employee who noted the agency was not the only player in the regional timber industry confirmed these beliefs. This employee noted that several large timber companies exist within the region and have the capacity to produce a greater supply of timber and therefore employ a much larger portion of the region's workforce.

\subsubsection{Social Organizations and Structure}

A comparison of the data from both case studies revealed that the types and purposes of existing social organizations varied relative to the community's social structure. For example, in Franklin ten 
social organizations were identified (i.e., collaborative groups, organizations, councils, or other forums available in the community enabling people to work together). All ten organizations were secular and half were service-oriented (e.g., the Kiwanis Club or the League of Women's Voters of Macon County). In contrast, in Louisville, most existing social organizations were tied to a specific religious institution and operated independent of one another. In Mississippi, even several secular organizations, such as the local Boys and Girls Club of America, that enabled individuals to work together and address common problems, had a religious affiliation. Civic organizations acting as pseudo-subsidiaries of local churches illustrate the strong religious ties and orientations frequently associated with individuals in rural southern communities [33].

\subsubsection{Information and Communication}

In Franklin and Louisville, the local newspaper appeared to be a largely underutilized resource for establishing the types of reciprocal relationships desired by the agency. In both study areas, the Forest Service rarely took advantage of the local news outlet to alert local community members about agency-sponsored events or community-sponsored events at which the agency had a presence. Flora and Flora [34] note that local newspapers in rural communities tend to provide little coverage of any substantive "news" and instead report on local gatherings (e.g., club meetings, fundraisers, service projects, etc.). Franklin residents, in particular, expressed a feeling of unawareness about what the agency was doing or how they could become involved if they chose to do so. An agency representative reported their office had numerous partnerships with local community businesses and organizations and was involved in various community-sponsored events. However, the agency did not appear to be capitalizing on their efforts to build social capital with local communities through notifications and articles in local newspapers.

\subsubsection{Collective Action}

Residents of Louisville and Franklin devote much of their time to volunteer efforts and community-oriented events. At least nine community-oriented events in Louisville and four in Franklin were identified. Community-oriented events, such as festivals and farmer's markets, can act as important contributors to local social capital development as they bring together a diverse spectrum of individuals from the community to interact for the specific purpose of improving local social and economic well being [35]. Most of the events in Louisville and Franklin were organized and operated by local volunteers and several were funded through statewide education or rural development efforts (e.g., the "Youth Tobacco-Free Celebration" held by The Mississippi Department of Health's Tobacco Free Coalition).

\subsection{Forest Service Checklists}

\section{Community Integration and Engagement}

In Franklin, workshop participants conveyed a general feeling of trust and good rapport between their community and the agency. However, several participants noted the amount of information conveyed by the agency, and the agency's commitment to open and reciprocal communication, was 
lacking. Workshop participants made several suggestions on how existing lines of communication could be bolstered. One such suggestion included provision of a live operator at the District Office to field calls from local residents. Participants also suggested creating an agency position with job responsibilities solely related to community involvement (including tracking and monitoring engagement efforts, which is not currently being done).

Residents of Louisville expressed similar concerns over the Forest Service's commitments to open lines of communication. Some of these concerns were validated by comments made by a Forest Service employee on the Tombigbee National Forest. The employee noted that community involvement and the potential to build social capital was a risk that did not need to be taken. This employee believed that what could be gained (i.e., increased Forest Service-community social capital) was not as great as what could be lost (i.e., the lack of controversy).

\section{Conclusions}

The primary objective of this paper was to present a data collection protocol that can be used by Forest Service personnel and social scientists to rapidly gather information concerning the strength of relationships which exist between the Forest Service and local communities. The intent was to provide agency personnel and other interested parties a tool that can be employed to quickly gather data on community/agency relationships. Ideally, this data can subsequently be used to inform policy and management decisions that depend on, or impact, local communities. I've attempted to illustrate the utility of the protocol by demonstrating its capabilities of identifying unique, context specific barriers and bridges to building successful collaborative relationships between the USDA Forest Service and local communities. The subsequent discussion focuses on the two study communities of Louisville, Mississippi and Franklin, North Carolina and attempts to illustrate the extent to which data and inference generated from the use of the rapid social capital assessment protocol can be used to inform local Forest Service policy and management decisions.

In both Franklin and Louisville, the relationship between the agency and local residents was not as strong as it could be. The existence of strong social cleavages between existing socio-demographic groups (primarily along racial and religious lines) likely make it more difficult for the agency to establish just, equitable and transparent lines of communication among a network of stakeholders. The presence of within-group solidarity around collective actions (i.e., community-oriented events and volunteer efforts) organized by civic-organizations was also noted. Many of these small civic-organizations have specific purposes and only a fragment of the population participates in these events. For example, many individuals volunteer for community events either because the events benefit a specific cause of interest to them, or because they are attached to the organization responsible for planning the event (e.g., religious organizations, athletic programs, etc). Events organized around specific interests typically attract a narrow sub-sample of the community's population. As a result, it is difficult for the agency to manage numerous, purpose-driven relationships.

One potentially fruitful avenue for Forest Service personnel attempting to develop lasting collaborative relationships with local communities may come from establishing a presence in local events and other activities aimed at celebrating local identity and youth development. The historical and emotional ties of local downtown areas, as well as their functional importance as gathering places 
where residents can come together can serve as a unique opportunity for the Forest Service to establish a presence in the local community. Through their presence at local community events, aimed at celebrating local society, the agency could redefine its role in the community; not as a bureaucracy-laden federal presence largely unconcerned with local social conditions, but rather as a distinct and concerned organization within the local society. It is important to note that the rapid social capital assessment protocol requires the investigator to assess these common, yet frequently overlooked, aspects of community life. Traditional, hypothesis-driven social science research methodologies such as questionnaires often ignore these factors, which can play a potentially important role in community/agency relationships.

A structural barrier to social capital development is the agency's role in local economic development. There is a direct association between the extent to which Forest Service lands contribute to local economic health and the ability of the agency to build strong relationships with local communities. Communities economically dependent on forest products from Forest Service managed lands are more likely to want a say in Forest Service decision-making. Conversely, local communities whose economies are driven by products that come from private forests or processing sites have less incentive to be involved in agency decision-making. Numerous private forest owners exist within the study areas, many of whom play a much larger role in local communities' economic well-being than the Forest Service does. With little perceived or actual dependence on forest products derived from agency-managed lands, the agency's ability to develop lasting social relationships with local residents is challenging.

Nevertheless, Forest Service lands do play a role in local communities' economic vitality and the agency should find ways to inform local communities about its genuine interest in local economies. For example, in both study communities, the agency infrequently used local newspapers to convey information from the agency. Similar findings have also been noted in previous mixed-methods case studies of community/agency relationships [36,37]. The agency could use local news outlets to communicate a whole host of economic and non-economic benefits and opportunities that nearby Forest Service lands provide for local communities. Conveying its interest and concern for community well being through local outlets can assist the agency in defining its identity within the community as well as lead to future collaborative relationships. Again, this is a finding that could easily go unrealized if a singular research method was employed as opposed to the mixed-method design outlined in the protocol.

Perceptual barriers also were identified. Namely, community residents believed the agency was not open to hearing their ideas or responding to their concerns. These feelings were expressed across both study communities. They were particularly associated with an undefined formal mechanism by which local residents could convey attitudes, ideas and information to the agency. Perhaps a more subversive perceptual barrier was noticed among Forest Service personnel who saw no utility in attempting to develop open lines of communication with local residents. Both of these perceived risks are not particularly unique to the southeastern United States. However, their presence deserves noting as they can present an insurmountable barrier to building social capital.

Despite the numerous identified barriers to social capital development, the southeastern United States may provide a unique context for social capital to be developed. In both communities, numerous collective action and volunteer opportunities were taking place. The presence of these collective 
actions suggest the residents of Franklin and Louisville want to be involved in and take action on issues and topics affecting their community's quality of life. The agency should see this local autonomy as a potentially untapped resource and grasp its opportunity to become a local stakeholder in the community's welfare, rather than the other way around. Similarly, the findings reveal strong feelings of local pride, particularly rooted in the communities' historical and social identity. Numerous forest-associated communities in the southeastern United States have histories rooted in the forest and the spaces managed by the Forest Service. This fact could serve the agency well in its attempts to build strong and enduring relationships with local residents. Realizing these local histories and how to parlay them into potentially stronger Forest Service - community linkages could prove to be a pivotal first step in building greater stocks of social capital.

In conclusion, nearly all Forest Service management decisions affect local human communities to some extent. Consequently, the agency has gradually increased its efforts to collaborate and communicate with these local communities in an attempt to mitigate the potentially negative impacts of management decisions and better understand local citizens' needs and desires. Unfortunately, however, the agency frequently has few tools and techniques to rely upon to assess the strength of relationships between themselves and the local populations. The development of the rapid social capital assessment protocol addresses this need by giving agency personnel and interested social scientists a standardized tool through which they can better understand local residents' unique connections to the Forest Service. As illustrated in the findings from the two pilot communities of Louisville, Mississippi and Franklin, North Carolina, many details and unique characteristics of Forest Service-community relationships can be identified and illustrated with the rapid social capital assessment protocol. Arguably, many of these important details and characteristics would go unidentified or underexplored if the agency and/or social scientists relied solely on a traditional singular methodology. The protocol combines multiple methodologies into a very rapid data collection process whereby specific community/agency connections can be identified, quantified and described. Identifying these unique connections and understanding how they either hinder or help the agency in meeting their mandates is a pivotal first step the development of collaborative relationships and more desirable Forest Service-community relationships.

\section{Acknowledgments}

This rapid social capital assessment protocol presented in this research was developed through joint support from the USDA Forest Service and the National Oceanic and Atmospheric Association. The author would like to acknowledge Stewart Allen (USDA Forest Service), Dorothy Anderson (NC State University), Mae Davenport (University of Minnesota), David Scarsella (Resource Dimensions, LLC), Julie Ann Gustanski (Resource Dimensions, LLC), Erin Seekamp (NC State University), David Bartecchi (Village Earth, LLC), Kathie Mattor (Colorado State University), John Russell (DOI Bureau of Land Management), and Deb Whitall (USDA Forest Service), for their involvement in both protocol development and testing.

\section{Conflict of Interest}

The author declares no conflict of interest. 


\section{References and Notes}

1. Leach, W.D. Public involvement in USDA Forest Service policymaking: A literature review. J. For. 2006, 104, 43-49.

2. USDA Forest Service. USDA Forest Service Final Programmatic Environmental Impact Statement: National Forest System Land Management Planning; USDA Forest Service: Washington, DC, USA, 2012.

3. Duane, T.P. Community participation in ecosystem management. Ecol. Law Quart. 1997, 24, 771-797.

4. Davenport, M.A.; Leahy, J.E.; Anderson, D.H.; Jakes, P.J. Building trust in natural resource management within local communities: A case study of the Midewin National Tallgrass Prairie. Environ. Manag. 2007, 39, 353-368.

5. Burns, M.; Cheng, A.S. Framing the need for active management for wildfire mitigation and forest restoration. Soc. Natural. Res. 2007, 20, 245-259.

6. Wondelleck, J.M.; Yaffee, S.L. Making Collaboration Work: Lessons from Innovation in Natural Resource Management; Island Press: Washington, DC, USA, 2000.

7. USDA Forest Service. USDA Forest Service National Forest System Land Management Planning; USDA Forest Service: Washington, DC, USA, 2005.

8. Bourdieu, P. The forms of capital. In Handbook of Theory and Research for The Sociology of Education; Richardson, J.G., Ed.; Greenwood Press: New York, NY, USA, 1986; pp. 241-258.

9. Coleman, J.S. Social capital in the creation of human capital. Am. J. Soc. 1988, 94, S95-S120.

10. Van Kooten, G.C.; Thomsen, R.; Hobby, T.G.; Eagle, A.J. Social dilemmas and public range management in Nevada. Ecol. Econ. 2006, 57, 709-723.

11. Davenport, M.A.; Anderson, D.H.; Leahy, J.E.; Jakes, P.J. Reflections from USDA Forest Service employees on institutional constraints to engaging and serving their local communities. J. For. 2007, 105, 43-48.

12. Steelman, T.A. Elite and participatory policymaking: Finding balance in a case of national forest planning. Policy Stud. J. 2001, 29, 71-89.

13. Abt, K.L.; Prestemon, J.P.; Gebert, K. Forecasting wildfire suppression expenditures for the United States Forest Service. For. Sci. 2008, 79, 341-360.

14. Farnham, T.J. Forest service budget requests and appropriations. Policy Stud. J. 1995, 23, 253-267.

15. Gericke, K.L.; Sullivan, J. Public participation and appeals of Forest Service plans: An empirical examination. Soc. Nat. Res. 1994, 7, 125-135.

16. Evans, A.; McKinley, G. An Evaluation of Fuel Reduction Projects and the Healthy Forests Initiative; Forest Guild: Santa Fe, NM, USA, 2007.

17. Laband, D.N.; Gonzáles-Cabán, A.; Hussain, A. Factors that influence administrative appeals of proposed USDA Forest Service fuels reduction actions. For. Sci. 2006, 52, 477-488.

18. Agrawal, S.; Monroe, M.C. Using and improving social capital to increase community preparedness for wildfire. In the Public and Wildfire Fire Management: Social Science Findings for Managers; U.S. Department of Agriculture, Forest Service, Northern Research Station: Newtown Square, PA, USA, 2006; pp. 163-167. 
19. Brenkert, H.; Champ, P.; Flores, N. Mitigation of Wildfire Risk by Homeowners; USDA Forest Service, Rocky Mountain Forest and Range Experiment Station: Fort Collins, CO, USA, 2005.

20. Cortner, H.J.; Moote, M.A. The Politics of Ecosystem Management; Island Press: Washington, DC, USA, 1999.

21. Yaffee, S.L.; Phillips, A.; Frentz, I.C.; Hardy, P.W.; Maleki, S.; Thorpe, B.; Nelson, G. Ecosystem Management in the United States: An Assessment of Current Experience; Island Press: Washington, DC, USA, 1996.

22. Keele, L. Social capital and the dynamics of trust in government. Am. J. Polit. Sci. 2007, 51, 241-254.

23. Leahy, J.E.; Anderson, D.H. Trust factors in community-water resource management agency relationships. Landsc. Urban Plan. 2008, 87, 100-107.

24. Smith, J.W.; Leahy, J.E.; Anderson, D.H.; Davenport, M.A. Community/agency trust and public involvement in resource planning. Soc. Nat. Res. 2012, in press.

25. Smith, J.W.; Leahy, J.E.; Anderson, D.H.; Davenport, M.A. Community/agency trust: A measurement instrument. Soc. Nat. Res. 2012, in press.

26. Hendee, J.C. Public opinion, and what foresters should do about it. J. For. 1984, 82, 340-344.

27. Lachapelle, P.R.; McCool, S.F.; Patterson, M.E. Barriers to effective natural resource planning in a "messy" world. Soc. Nat. Res. Int. J. 2003, 16, 473-490.

28. Selin, S.W.; Schuett, M.A.; Carr, D.S. Has collaborative planning taken root in the national forests? J. For. 1997, 95, 25-28.

29. Beebe, J. Basic concepts and techniques of rapid appraisal. Hum. Organ. 1995, 54, 42-51.

30. US Census Bureau 2008 Population Estimates. Available online: http://factfinder.census.gov (accessed on 20 August 2009).

31. Employment data was gathered from the Bureau of Economic Analysis (www.bea.gov) where it is aggregated at the county level. This data is the most precise available, given the Bureau of Economic Analysis as well as the U.S. Census censors municipal-level data for small cities to avoid disclosure pertaining to a specific organizations or individuals.

32. Nelson, P.B. Geographic perspective on amenity migration across the USA: National-, regional-, and local-scale analysis. In The Amenity Migrants: Seeking and Sustaining Mountains and Their Cultures; Moss, L.A.G., Ed.; CABI Publishing: New York, NY, USA, 2006; pp. 55-72.

33. Glenna, L. Religion. In Challenges for Rural America in the Twenty-First Century; Brown, D.L., Swanson, L.E., Eds.; Pennsylvania State University Press: University Park, PA, USA, 2003; pp. 262-273.

34. Flora, C.B.; Flora, J.L. Rural Communities: Legacy and Change; Westview: Boulder, CO, USA, 2008.

35. Wilkinson, K.P. The Community in Rural America; Social Ecology Press: Middleton, WI, USA, 1999.

36. Smith, J.W.; Anderson, D.H.; Moore, R.L. Social capital, place meanings, and perceived resilience to climate change. Rural Soc. 2012, 77, 380-407. 
37. Smith, J.W.; Moore, R.L.; Anderson, D.H.; Siderelis, C. Community resilience in Southern Appalachia: A theoretical framework and three case studies. Hum. Ecol. 2012, 40, 341-353.

(C) 2012 by the authors; licensee MDPI, Basel, Switzerland. This article is an open access article distributed under the terms and conditions of the Creative Commons Attribution license (http://creativecommons.org/licenses/by/3.0/). 